AATS Aortic Symposium 2018

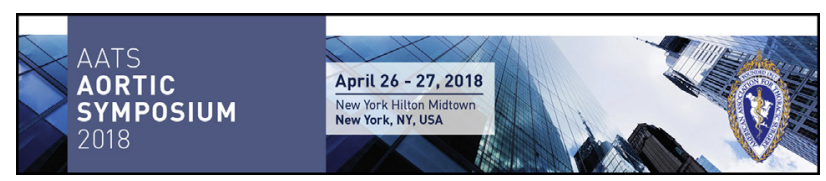

Registration \& Housing Now Available

\section{AATS AORTIC SYMPOSIUM 2018}

April 26-27, 2018

New York Hilton Midtown Hotel

New York, NY, USA

\section{Course Directors:}

Joseph S. Coselli

Steven L. Lansman

\section{Co-Directors:}

Joseph E. Bavaria

Edward P. Chen

Leonard N. Girardi

Thomas G. Gleason

G. Chad Hughes

Eric E. Roselli

David Spielvogel

Thoralf M. Sundt III

\section{Program Overview}

AATS Aortic Symposium 2018 is a two-day symposium focused on the pathophysiology, diagnosis, and treatment of aortic aneurysms and dissections. This conference is designed for cardiovascular and thoracic surgeons, residents, perfusionists, ICU and OR nurses, and those involved with the care of individuals with aortic disease. The faculty consists of world leaders in this field who have been invited to share their experience regarding difficult problems in aortic disease.

\section{Abstract \& Video Submission Deadline: \\ Monday, December 18, 2017, by 11:59 PM EST}

For more information, visit: aats.org/aortic

\section{AATS Surgical Patient Safety Course 2018}

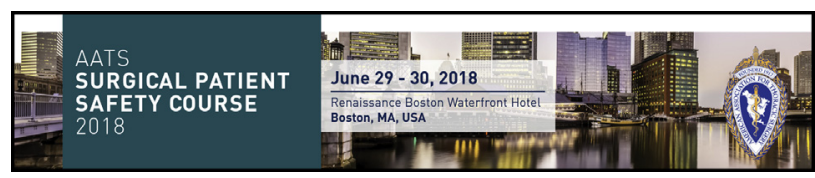

SAVE THE DATE

June 29-30, 2018

Renaissance Boston Waterfront Hotel

Boston, MA

In collaboration with the American Society of Extracorporeal Technology (AmSECT) and Association of Physician Assistants in Cardiovascular Surgery (APACVS)

Improving patient care remains a constant mission for all members of the surgical team. The AATS Surgical Patient Safety Course has been designed to promote a culture of safety and reduce preventable patient harm by engaging, educating and equipping members of the cardiothoracic surgical team in the multidimensional approach to patient safety. The course will provide attendees with the essential knowledge, skills and attitudes about patient safety that can improve care in the present and future.

"[This meeting] gave me much to think about in the way we deal with errors and try to learn from them, this has already subtly changed my approach."

—Previous Attendee

\section{Program Directors}

James H. Abernathy III, MD, Johns Hopkins Medicine

Thoralf M. Sundt III, MD, Massachusetts General Hospital Steven Yule, PhD, Brigham \& Women's Hospital/Harvard University

\section{Program Committee}

David J. Bunnell, PA-C, Washington DC VA Medical Center David Fitzgerald, MPH, CCP, Medical University of South Carolina

Robert D. Jaquiss, MD, University of Texas Southwestern Marco A. Zenati, MD, Harvard Medical School

\section{The AATS Graham Foundation}

Invest in the Future

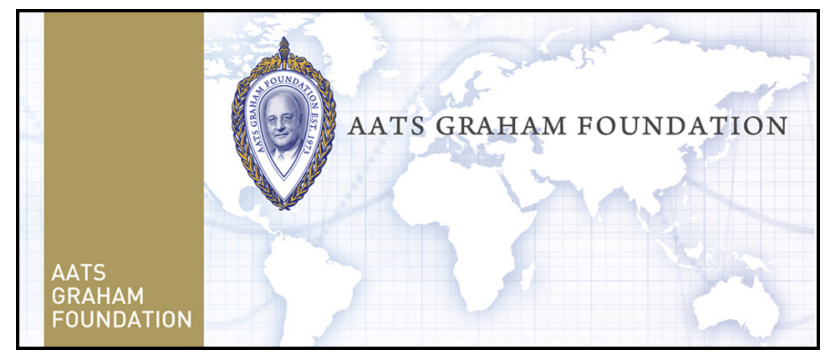

Every day, CT surgeons transform the lives of their patients around the world. Your support is essential to ensure the future of our specialty and continue advancing global innovation in CT surgery. Please make a gift to the Graham Foundation or renew your commitment. Together, we can promote our specialty not only for the next generation of surgeons, but also the patients they serve.

Learn more about individual and corporate/organizational giving opportunities.

Visit the Graham Foundation Web site: www.aatsgra hamfoundation.org 